\title{
The Drug Approval Process in the U.S., Europe, and Japan
}

\author{
Ines M. Vilas-Boas, C. Patrick Tharp
}

\section{OBJECTIVE:}

To describe the formal drug approval processes in the three major pharmaceutical markets in the world, and to examine their major differences. The article discusses some marketing and economic implications of efforts to provide greater uniformity on an international basis.

\section{DATA SOURCES:}

Literature and Internet references, interviews with government officials.

\section{DATA SYNTHESIS:}

Not applicable.

\section{CONCLUSION:}

Efforts to bring uniformity to the regulation of the international drug industry are bringing pressure on the U.S. FDA to change, and should be supported by the world medical community.

KEY WORDS:

FDA, EMEA, Koseisho, Statutory criteria, Marketing authorization

J Managed Care Pharm 1997; 3: 459-465
The United States historically has been the world's largest market for pharmaceuticals. However, this lead has been narrowing as managed care and generic substitution in the U.S. have slowed the growth of the drug industry by some economic measures. Access to the U.S. market de-mands compliance with Food and Drug Administration (FDA) requirements. Since 1962, however, there has been an international 'drug lag' between the U.S. and Europé, where pharmaceutical companies sometimes have attained marketing approval prior to attaining it in the United States. Until now, the U.S. has been the world's largest market and the FDA's position as the 'gold standard' for determining a drug's safety and efficacy has gone unchallenged. However, the creation of a single market in Europe (making it larger than the U.S. market) and the opening of the European Medicines Evaluation Agency (EMEA) in January 1995 has challenged the FDA's leadership, putting the agency under substantial pressure to change.
The pharmaceutical industry has a responsibility to its shareholders to seek the most financially attractive: market; which historically has been the U.S. ${ }^{1}$ Differences in the European, Japanese, and American regulatory systems have profound effects on which of the three markets is the most attractive from a financial point of view, and pharmaceutical companies are more likely to gear their research and development (R\&D) efforts to comply with the regulatory requirements of that market. The regulatory agency for that market is then in a position to become the regulatory 'gold standard' for the global market.

The International Harmonization Conference (ICH) is an effort by the governments and drug industries of the U.S., the European Union, and Japan to integrate the global regulation of pharmaceuticals, to provide greater uniformity of drug approval procedures and manufacturing standards, and regulation between countries. This global gold standard undoubtedly will influence the outcome of the

INES M. VILAS-BOAS, M.T., Graduate Student, Division of Pharmaceutical Policy and Evaluative Sciences, School of Pharmacy, University of North Carolina, Chapel Hill. C. PATRICK THARP, Ph.D., R.Ph., President, The Melling Group, an international pharmaceutical consultancy with offices in the U.S., United Kingdom, Germany, and Japan

The authors also wish to thank Mr. Tetsuya Takada, M.S., R.Ph., of The Melling Group/Japan in Tokyo, who supplied information regarding Japan's new drug approval procedures and who contacted various Koseisho authorities regarding some of the specific items reported in this article.

AUTHOR CORRESPONDENCE: C. Patrick Tharp, Ph.D., R.Ph., The Melling Group, 1334 Whispering Pines Drive, St. Louis, MO 63146

A CE CREDIT: This is article number 233-000-97-006-HO4 in AMCP's continuing education program. It affords 1.0 hour (0.1 CEU) of credit. Learning objectives and test questions follow on page 466.

Copyright 1 1997, Academy of Managed Care Pharmacy, Inc. All rights reserved. 
Figure 1. FDA Review Process for New Drug Applications

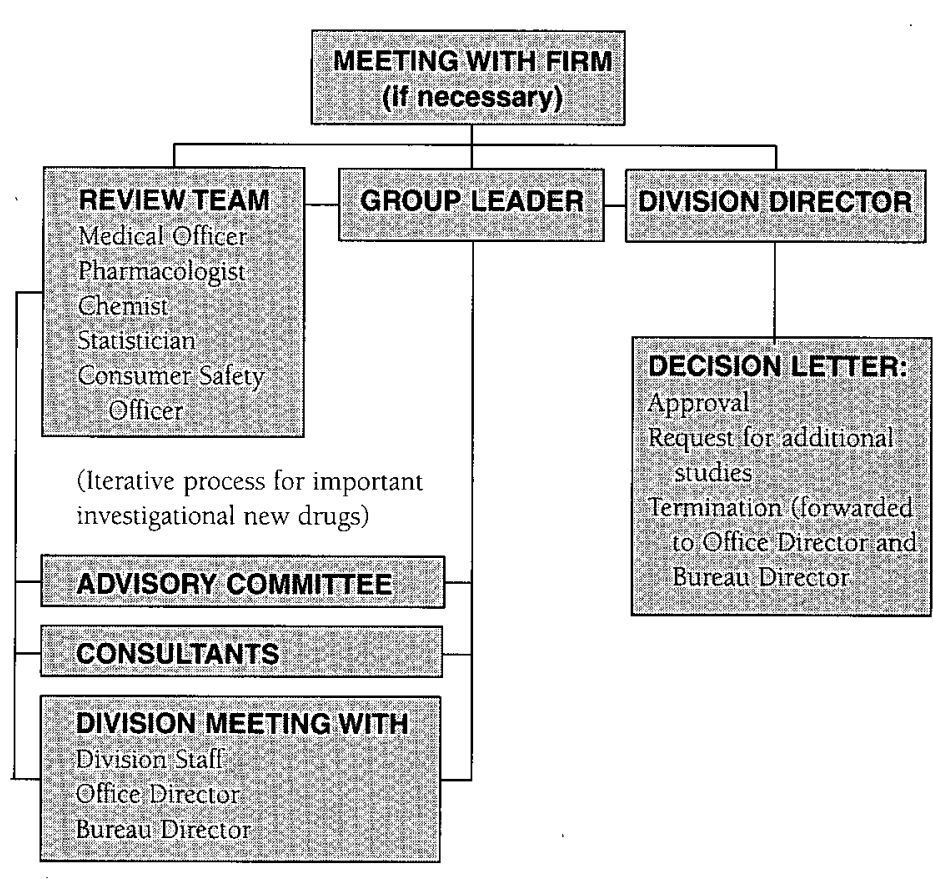

SOURCE: Report on the Food and Drug Administration's Process for Approving New Drugs, House Subcommittee on Science, Research, and Technology, 1980: 18.

negotiations within the ICH, thus having a profound effect on the global market. Furthermore, many nations model their pharmaceutical legislation after this standard.

This article will consider the structural and operational similarities and differences between the regulatory bodies involved in the negotiations and analyze the differences between the three major agencies in Europe, the U.S., and Japan, as well as factors that determine a market's profitability. This article also will analyze the impact of the FDA's and the Koseisho's lack of specified approval time versus the EMEA's stipulated approval time. It will evaluate the differences in time to obtaining authorization in these markets, as well as estimate the costs of submission through the three agencies Finally, this article will explore the differences between the regulating agencies' statutes and compare how these differences relate to R\&D expenditures and market profitability.

\section{THE FDA}

Federal controls over the U.S. drug supply began with the inspection of drugs imported into the U.S. in 1848. In 1862 President Lincoln created the Bureau of Chemistry in the new Department of Agriculture, which eventually became the Food and Drug Administration within the Department of Health and Human Services. In 1938 Congress passed the Federal Food, Drug, and Cosmetic Act requiring new drugs to be shown safe before marketing. In 1962, in light of the thalidomide incident, the Kafauver-Harris Amendments were passed to ensure greater drug safety. This legislation required U.S. drug manufacturers to show the effectiveness and safety of their products before marketing them. ${ }^{2}$

The FDA has a standard procedure for drug approval and most drugs must go through this process. (Orphan drugs are an exception, but they will not be addressed here.) After the completion of controlled clinical trials under an Investigational New Drug (IND) status, exemption pharmaceutical companies seeking marketing approval of their products in the U.S. must submit a New Drug Application (NDA) to the FDA. The NDA review process is conducted in house by teams within the FDA, as indicated in Figure 1, with each team responsible for reviewing drugs in a particular therapeutic class. ${ }^{3}$ At the end of the lengthy review process, the company is issued a decision letter, which may be an approval letter, a request for additional studies, or a termination letter.

\section{THE EMEA}

The European Union (EU), previously known as the European Community, originated in 1952 when six countries-Belgium, France, the Federal Republic of Germany, Italy, Luxembourg, and the Netherlands-created the European Coal and Steel Community (ECSC) by pooling their coal and steel resources in a common market controlled by an independent supranational authority. In 1958 the Rome Treaties set up the European Economic Community (EEC), extending the common market to all economic sectors in the member countries. In 1973 the United Kingdom, Ireland, and Denmark joined the Community; in 1981 it was Greece's turn, and in 1986 Portugal and Spain followed suit. In January 1995 Austria, Finland, and Sweden joined the Union, thus bringing the number of member states to $15 .{ }^{4}$

In 1965 the first European Economic Community (EEC). Directive (a recommended policy used to integrate and con- . solidate procedures within the EU member countries) was issued on the regulation of medicinal products. Since then numerous other directives, regulations, and guidelines have been issued by the Council of the European Union, the European Parliament, and the European Commission. These efforts strive to bring about the harmonization of European laws regarding pharmaceuticals and, ultimately, the creation of a unified market in Europe. ${ }^{5}$

In January 1995 a new European system for the authorization of medicinal products came into effect, and the European Agency for the Evaluation of Medicinal Products (EMEA) was established in London by the European Council. This agency intends to promote the free circulation of pharmaceuticals within the EU while reinforcing the protection of public health.

The working bodies of the EMEA are the Management Board, two Scientific Committees, and a Permanent 
Secretariat. The Management Board, EMEA's governing body, is responsible for the budget and for ensuring appropriate coordination of the natural resources of the member states. This Board consists of two representatives from each of the 15 member states, two representatives of the European Commission, and two representatives appointed by the European Parliament.

The two Scientific Committees-the Committee for Proprietary Medicinal Products (CPMP) and the Committee for Veterinary Medicinal Products (CVMP)—oversee applications for drugs for human consumption and veterinary products, respectively. Each of these committees consists of two representatives from each member state who are appointed based on their roles and experience in medicinal product evaluation.

The Permanent Secretariat is comprised of roughly 100-150 staff members who provide general administrative and logistical support to the Scientific Committees and the Management Board. The EMEA has over 1,600 outside expert reviewers who are contracted to review applications. ${ }^{6}$ To minimize bias prior to their appointments, these experts undergo a thorough screening process that includes the disclosure of any ties to the industry, academic institutions, or industry interest groups.

Pharmaceutical companies seeking approval of their products in the European Union currently have a choice of three different regulatory procedures: national, decentralized, and centralized applications. National applications are processed by each member state and are subject to the respective national legislation regarding pharmaceuticals. Under this national procedure, marketing approval is granted only for the member country where marketing authorization was sought. Furthermore, applications processed at the country's level are not subject to time-of-approval guidelines set by the EU. The national application procedure is to be phased out in 1998.

The decentralized procedure is based on the principle of mutual recognition of national authorizations. ${ }^{78}$ In this procedure the applicant seeks approval in a member country. After approval is granted, that country then refers the application to other EC countries chosen by the applicant. Should a national authorization not be recognized, the dispute is submitted to the EMEA for arbitration. This procedure takes a maximum 358 days after the first authorization is granted (see Figure 2).

The centralized procedure was introduced in January 1995. Use of this procedure is compulsory for medicinal products derived from biotechnology (see Appendix, page 465) and available for other innovative new products at the request of companies. These applications are submitted directly to the EMEA in London. This procedure takes up to 388 days and grants a single market authorization applicable to the entire European Union (see Figure 3). In the future, this procedure will be recommended for all pharmaceuticals seeking marketing authorization in Europe as the other two procedures are phased out.

The choice of European procedures depends on (1) the pharmaceutical company; (2) its product; and (3) the market it
Figure 2. The EMEA's Decentralized Procedure

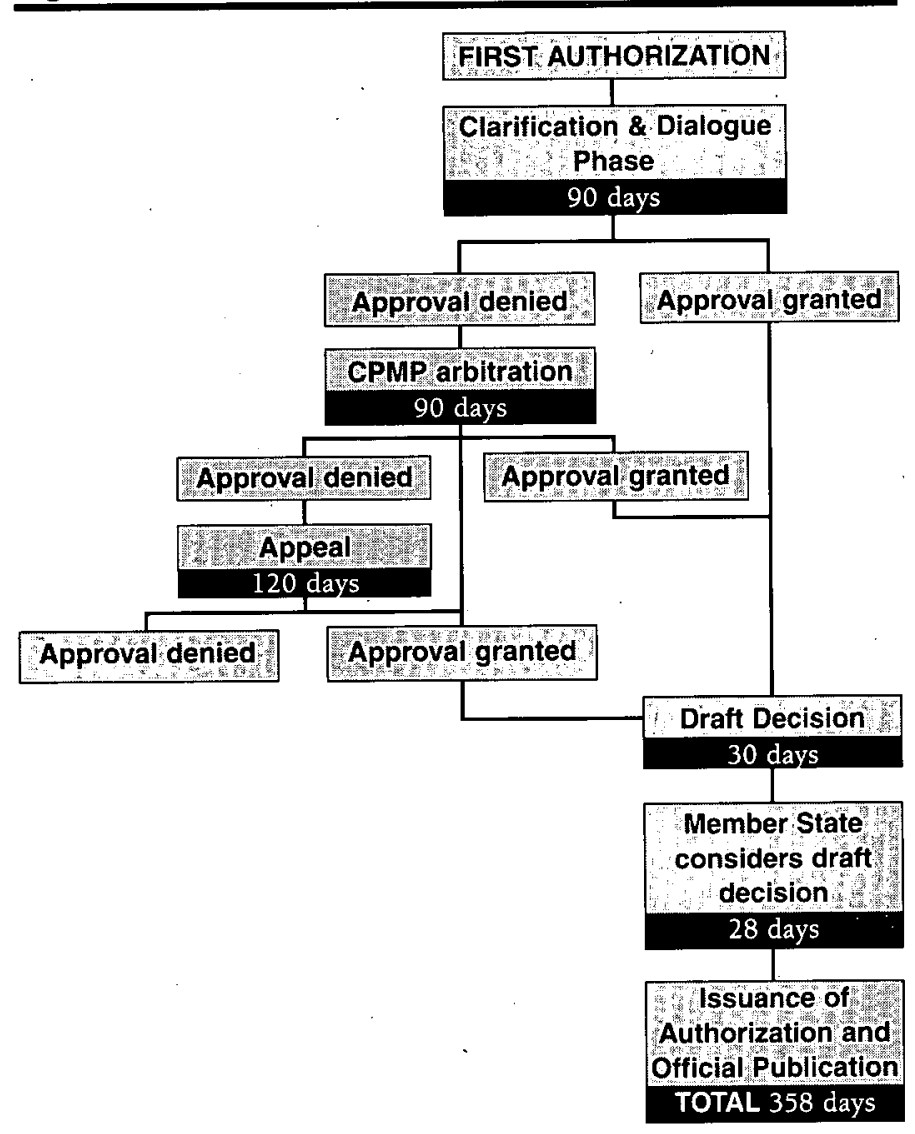

Figure 3. The EMEA's Centralized Procedure

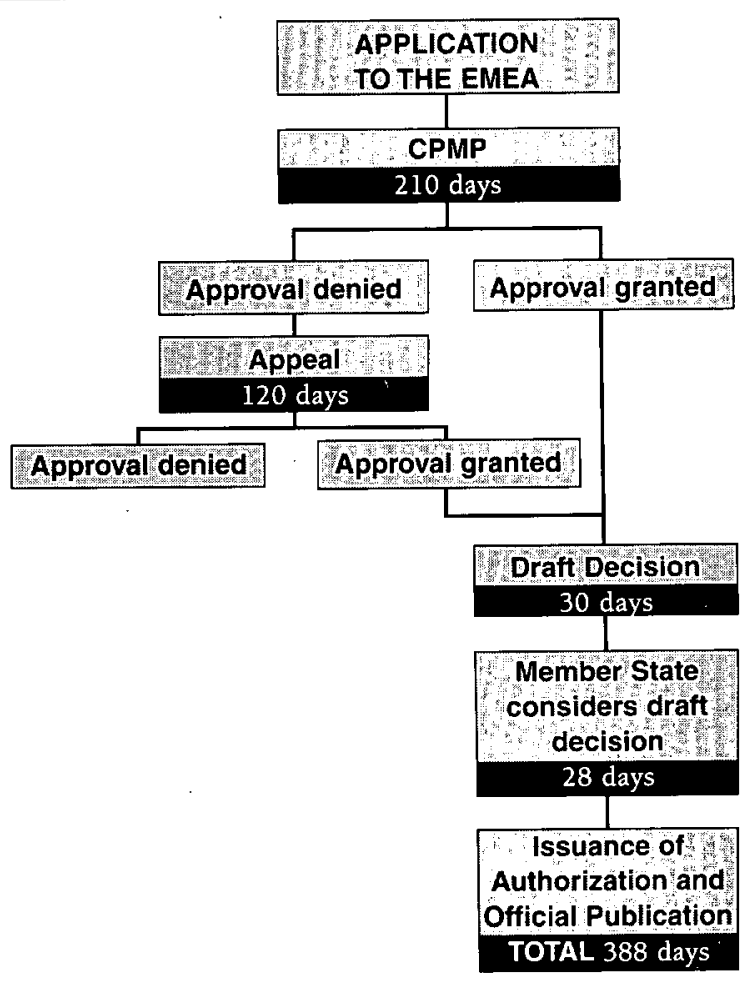


Figure 4. Koseisho Review Process for New Drug Applications

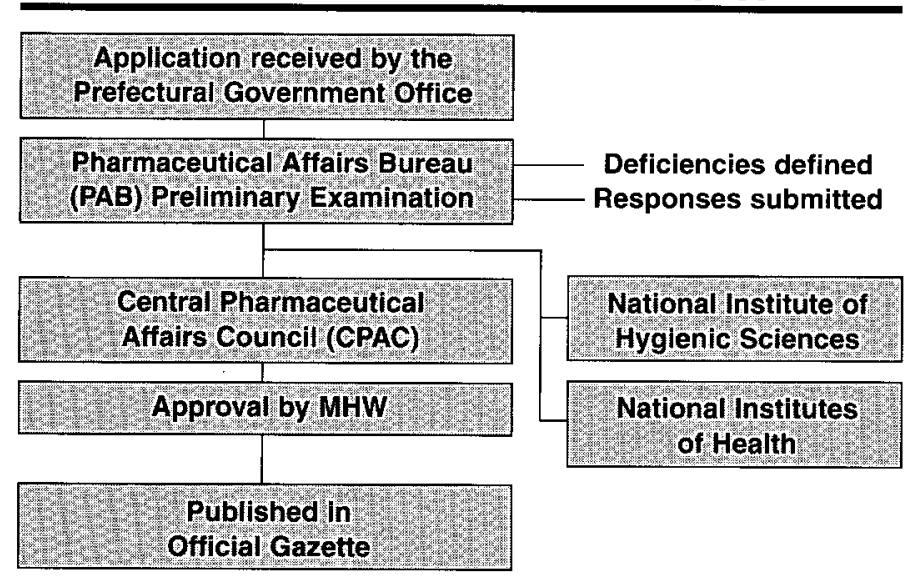

SOURCE: Currie WJ Drug Development and Registration in Japan: Threshold of Transition, Journal of Clinical Pharmacology 1993, 33:100-08.

intends to reach. Biotechnology products have no choice and must submit their approval requests through the centralized procedure directly to the EMEA. The choice for innovative new products depends on a number of factors. If the product is an orphan drug or the company is small and has limited resources, the centralized procedure may be more appropriate. If the targeted market does not include all the member states, the decentralized procedure may be more appropriate. Other issues that might influence this decision include the length of the remaining patent life, proposed indications, and whether or not second-applicant patent protection is available in the member countries where marketing authorization is sought. ${ }^{9}$

\section{THE KOSEISHO}

The Japan Ministry of Health and Welfare (the Koseisho, pronounced koe-say-show) was established as a governmental administrative body under the Japanese constitution that was framed after World War II. The Ministry is responsible for the operation of the National Health System of Japan, national regulation of hospitals and other health facilities, registration and regulation of many of the health professions, approval and surveillance of drug products, and other regulatory matters. The Koseisho also administers the reimbursement of providers, including those who prescribe and dispense in the mostly physician-controlled health delivery system.

In Japan, pharmaceutical companies are required to do clinical effectiveness and safety studies on a population of Japanese patients. This policy makes it a great deal more difficult for overseas companies to complete their Japanese new drug applications. On the other hand, the Koseisho recently has issued statements suggesting that it will be more permissive about allowing the submission of foreign clinical studies in support of new drug applications. The registration proce-
Figure 5. Comparing the U.S., the EU, and Japan

\begin{tabular}{|c|c|c|c|}
\hline & EU-15 & U.S. & Japan \\
\hline Area (1000 sq miles) & 1249 & 3732.4 & 945.3 \\
\hline Population (millions) & 370.5 & 258.3 & 124.9 \\
\hline Unemployment Rate, 1994 & 11.2 & 6.1 & 3.1 \\
\hline Gross Domestic Product (billions) & 7293.8 & 6638.2 & 4500 \\
\hline GDP (volume)\% increase $94 / 93$ & 2.6 & 3.9 & 0.9 \\
\hline Aid to third world ( $\$$ billion, 1992) & 33.5 & 11.7 & 14.5 \\
\hline $\begin{array}{l}\text { Exports } \\
\quad(\$ \text { billions, 1992) }\end{array}$ & $\begin{array}{c}661.7 \\
(16.9 \% \text { to US) }\end{array}$ & $\begin{array}{c}551 \\
(17.7 \% \text { to EU })\end{array}$ & $\begin{array}{c}433 \\
(27.3 \% \text { to US })\end{array}$ \\
\hline $\begin{array}{l}\text { Imports } \\
\text { (\$ billions, 1992) }\end{array}$ & $\begin{array}{c}745.5 \\
(17.8 \% \\
\text { from US) }\end{array}$ & $\begin{array}{c}626.6 \\
(22.9 \% \\
\text { from EU) }\end{array}$ & $\begin{array}{c}364 \\
(22.6 \% \\
\text { to US) }\end{array}$ \\
\hline
\end{tabular}

dure for foreign companies may become less time consuming in the future, especially if such companies form a joint venture, comarket or codevelop, or cross-license with a Japanese company. Figure 4 shows the organization of the Koseisho's review process.

\section{THE THREE MARKETS}

The FDA, the Koseisho, and the EMEA all have an identical mission: to allow pharmaceuticals to reach the market while protecting public health. However, they carry out this mission in different ways, and these differences can have a significant economic impact on the pharmaceutical industry and ultimately on the markets they oversee. Figure 5 provides some basic statistics of the markets. ${ }^{10}$

\section{TIME TO APPROVAL}

The EMEA guarantees that an application for marketing approval through the centralized procedure will be completed in seven to 13 months, depending on the need for appeals and clarification. Neither the FDA nor the Koseisho specify or guarantee a time frame within which a firm can expect a verdict. In Japan the average time for approval of a new drug application for marketing is two to three years. Although the average review time in the FDA has decreased from 36 to 22 months, this is still almost twice the time it takes the EMEA to review an application. This lag in approval between the agencies translates into an economic loss for the pharmaceutical company. A patented drug may have average worldwide șales of $\$ 1$ million a day, with Europe now accounting for approximately $30 \%$ of the global market. Adding only one year to the sales life of a new drug can generate more than $\$ 300$ million in revenues. ${ }^{11}$ Thus, the quicker a patented drug reaches the market, the more profitable that drug will be because of the longer period without generic competition.

Although many companies have been seeking marketing authorization in Europe prior to the U.S. for quite some time, 
this added economic incentive, along with the growth of the European market, might lead companies to restructure their R\&D efforts to comply with the EMEA, as opposed to having the individual European nations design their pharmaceutical regulatory agencies around the FDA's gold standard as has been done historically. In Japan, the R\&D effort often must be directed toward the development of a customized Japanese product. The Koseisho often concentrates a majority of its effort on the safety, rather than the efficacy, of a new product. As a consequence of this regulatory emphasis and Japanese cultural perceptions, the dose of any pharmaceutical product is often lower in Japan than in western-hemisphere markets, and combination drug products are more common in Japan than in the U.S. and most EC countries. These factors necessitate careful market research prior to the development of a new product for the Japanese market.

\section{COST OF SUBMISSION}

The U.S. Prescription Drug User Fee Act of 1992 allows the FDA to collect a user fee for the review process. ${ }^{11}$ The fees levied on the pharmaceutical company include an application fee, an annual establishment fee, and an annual product fee (see Figure 6). The annual establishment fee is levied on any business that makes at least one prescription drug product at one physical location or more than one building within five miles of each other. The product fee is levied on each specific strength or potency of a prescription drug that has an approved human drug application.

The EMEA has a slightly different fee structure. ${ }^{12}$ Companies pay an initial application fee; once the application is approved, an annual maintenance fee must be paid. Marketing authorizations in Europe are granted for a five-year period. Every five years thereafter a regulatory review of the product is conducted and companies must pay a five-year renewal fee to keep the product on the market. The total cost of marketing approval in Europe under the centralized system has a ceiling of $\$ 250,000$, about half of what it would cost to pay all 15 individual national fees. ${ }^{13}$ There currently are no registration fees or renewal fees charged by the Ministry of Health and Welfare in Japan on pharmaceutical products.

A comparison between these fee structures shows that to keep one dosage form of one product on the market in the U.S. for five years costs a company $\$ 937,000$, while in Europe it will cost $\$ 262,500$. These figures only represent application and marketing costs paid directly to the regulatory agency and account only for a small portion of the total cost of keeping a drug on the market. While for a large corporation this sum might not be significant, it would be a tremendous burden for smaller firms, especially if they have more than one dosage form and more than one product on the market. The relatively higher costs imposed on companies by the FDA's fee structure might be an incentive for firms to concentrate on the European market first. This further threatens the FDA's posi-
Figure 6. FDA, EMEA, and Koseisho Fee Structures

\begin{tabular}{|c|c|c|c|c|}
\hline FDA & & EMEA & & Koseisho \\
\hline Application fee & $\$ 208,000$ & Full application & $\$ 175,000$ & No Fees \\
\hline \multirow[t]{2}{*}{$\begin{array}{l}\text { Supplements } \\
\text { and applications } \\
\text { w/out clinical data }\end{array}$} & $\$ 104,000$ & $\begin{array}{l}\text { For each } \\
\text { additional } \\
\text { form/dosage }\end{array}$ & $\$ 25,000$ & \\
\hline & & Five year renewal & $\$ 12,500$ & \\
\hline Establishment fee & $\$ 126,000$ & Arbitration & $\$ 37,000$ & \\
\hline Product fee & $\$ 12,000$ & $\begin{array}{l}\text { Annual } \\
\text { maintenance } \\
\text { fee }\end{array}$ & $\$ 37,500$ & \\
\hline
\end{tabular}

tion as the gold standard since pharmaceutical companies can now reach the larger market faster and at a reduced cost, thus recovering $R \& D$ expenditures earlier.

\section{STATUTORY CRITERIA}

From a public health point of view, there is an earnest concern for the safety of the products that reach the market. To gain FDA approval, a new drug must satisfy statutory standards of both safety and effectiveness. Section 505(d) of the Food, Drug, and Cosmetic Act requires that a drug must be proven "by all methods reasonably applicable" to be "safe for use under the conditions prescribed, recommended, or suggested in the proposed labeling." The FDA also requires sponsors to submit "substantial evidence" of the drug's efficacy. Based on these standards, the FDA decides to approve or reject each application. The EMEA, on the other hand, requires "adequate" evidence of safety, efficacy, and quality, suggesting that a single clinical trial might serve as sufficient evidence in the EU system. The FDA, by contrast, still interprets its statutes as requiring at least two pivotal studies:

In Japan, there is no official written standard, but the experience of companies applying for approval in Japan indicates that the government is rather strict in its requirements, particularly in regard to human safety and side effects. For decades, the Koseisho has required the inclusion of clinical studies involving Japanese subjects among those submitted. This is designed to determine if this population might experience any differences in metabolism, side effects, or sensitivities to the new product.

These statutory approval criteria are highly correlated to the R\&D expenditures of pharmaceutical companies. If the companies spend less on $R \& D$, the overall development cost of the drug will be lower, making sales in the market with the least requirements more profitable. Since Europe historically has required less restrictive testing, it can be less costly overall to develop a product in the EU as opposed to the U.S.

Clearly, all drug regulatory agencies, through their statutory requirements, are concerned with consumer safety. Some 
would argue that the EMEA's criteria are not as strict as the FDA's, and thus question whether the products that reach the EC market are entirely safe and efficacious. However, research suggests that regulatory systems in other industrialized countries, whose systems may not be as strict as the FDA, achieve comparable safety levels while avoiding the delays of the American system. ${ }^{14}$ With regard to other safety issues, such as periodic safety reports and post-marketing reporting of adverse drug reactions, the FDA, the Koseisho, and the EMEA are not significantly different.

\section{OTHER REGULATORY AND MARKETING DIFFERENCES}

In most countries other than the United Kingdom and the United States, pricing of pharmaceutical products is strictly regulated by the government. In the U.K., payment for most prescription drugs is made at least in part by the National Health Plan; the same is true in Japan and most European countries. In the U.K., there are regulations regarding how much companies can spend on advertising and promotion and limits on the overall profit the company can make in a year, but the pricing of individual products is left mostly to the companies. When countries have a national health plan covering pharmaceutical care, then pharmaceutical companies have practically no influence on the product decisions of payors, unlike the U.S., where pharmaceutical companies can vertically integrate with insurance companies or managed care organizations.

Cost-effectiveness or other pharmacoeconomic claims are another area of wide disparity between countries. In Scandinavia, where nearly all drugs are paid for by the government, a lot of attention is given to economic implication studies in the governments' decisions on drug pricing. The degree of sophistication of the Swedish pricing authority, for example, is quite high, even to the point of permitting a higher price than exists elsewhere for the drug if it can be shown that its use reduces overall health care costs or the need-for additional or costly alternative treatments such as surgery. In Japan, pharmacoeconomic studies are only beginning to be considered by either the approval process or the pricing authorities in the Koseisho. In the U.S., such studies are sometimes reviewed by the FDA as part of its oversight of the advertising and promotional practices of the industry.

These three major markets also differ in the regulation of so-called 'off-label' uses of pharmaceutical products. In the U.S., physicians and other prescribers can prescribe a drug product for any use or treatment and expect no government intervention. The same is true in the U.K. In either country, if the payment for the drug is to be made by government or health insurance programs, it is possible that reimbursement might be delayed or refused, except for approved indications. In EC countries, which have government-paid health plans, and under Japan's National Health Plan, reimbursement usual- ly is granted only for conditions for which the drug is labeled after government approval. Thus, off-label uses generally are not permitted in countries that have a national health plan covering pharmaceutical products.

Although all countries use modern drugs, there are very significant differences in the types of drugs used, the amounts consumed, and the perception the health care community and the consumers have of the usefulness of new products. For example, in Germany, the Netherlands, and some other EC countries, there is a heavy emphasis on the use of natural remedies such as extracts, teas, and concentrates that are prescribed by the medical practitioners in lieu of or in addition to modern synthetic or semi-synthetic pharmaceuticals. Likewise, in Japan, it is common practice for physicians to prescribe herbal remedies or other natural products. Additionally, Japanese products often include herbal or other natural ingredients in addition to the 'modern' drug in the same preparation. Because of such market and cultural differences from country to country, it is important for the pharmaceutical company to conduct careful market research before $R \& D$ begins to develop a product to be submitted for approval. These differences also affect the time it takes to develop, test, . and gain marketing approval, as well as the perception of what is a fair price.

\section{CONCLUSION}

There are many factors that determine what makes one market more profitable than another. As the current gold standard, the FDA is under tremendous pressure to change and to keep up with the changes and demands of the global market. Already, special procedures have been instituted to reduce the approval time of orphan drugs, AIDS drugs, and other innovative products. However, some critics of the FDA have suggested deregulating entry procedures to allow the American public even faster access to new drugs. Others have suggested that the creation of the EMEA presents a new opportunity for international cooperation, regulatory harmonization, and mutual recognition of new drugs. The FDA must change, and it must improve to meet a demanding global market, which calls for quick access to safe and efficacious new drugs at the lowest cost to the public. The EMEA has been operational for just over a year, but it already is getting accolades and global attention. Only time will tell whether EMEA can become the gold standard in the global pharmaceuticals regulation arena.

Several factors necessitate processes that will enable more rapid, yet prudent, approval of new drug products for public consumption. These include the growth of the elderly population, the dramatic increase of governmental expenditures around the world for health care, including pharmaceuticals, and the need to reduce health care costs through improved drug therapy, government-regulated prices, formularies, and other means such as managed care.

The efforts of the European Community and the U.S. to 
harmonize pharmaceutical regulations between countries and provide mutual recognition of new drug approvals is a noteworthy effort that deserves the support of the world medical community.

\section{References}

1. Katz EM. Europe's centralized new drug procedures: Is the United States prepared to keep pace? Food and Drug Law Journal (1993); 48: 577-87.

2. <http://www.fda.gov/opacom/hpview.html> April 14th, 1996.

3. Grabowski HG, Vernon JM. The Regulation of Pharmaceuticals.

Washington, DC: American Enterprise Institute, 1983

4. Davidson, J. The European Union: A guide to Washington, DC, 1994

5. <http://www.eudra.org/w3/Index.html> March 13th, 1996.

6. Pharmaceuticals: "Success" in first year for EU medicines agency. Europe Information Service. 1996, February 20

7. Kingham RF, Bogaert PWL, Edy, PS. The new European Medicines Agency

Food and Drug Law Journal 1994; 49; 301-21.

8. Anonymous. New Drug Agency Opens. Managing Intellectual Property 1995, (March); 8-9.

9. Anonymous. EU market approvals which route to choose.

Marketletter 1995 (February 27).

10. Green D. Fast-track approval for new drugs raises industry doubts.

Financial Times 1995 (January 26); 2.

11. <http:/www.fda.gov/fdac/special/newdrug/feetabl.html> March 16th, 1996.

12. Sauer. EMEA "Will not be European FDA". Marketletter 1995

(February 6).

13. Koberstein W, Fernand Sauer. Tending the garden. Pharmaceutical Executive 1996; 16: 46-52.

14. FDA reform and the European Medicines Evaluation Agency. Harvard Law Review 1995 (June); 108: 2009-26.

\section{APPENDIX}

The products described in part A must go through the centralized approval procedure of the EMEA. The products in part B may attain permission to go through the centralized procedure of the EMEA.

\section{PART A}

A Medicinal products developed by means of one of the following biotechnology processes:

A recombinant DNA technology;

$\Delta$ controlled expression of genes coding for biologically active proteins in prokaryotes and eukaryotes including transformed mammalian cells; or

$\Delta$ hybridoma and monoclonal antibody methods.

$\boldsymbol{\Delta}$ Veterinary medicinal products, including those not derived from biotechnology, intended primarily for use as performance enhancers in order to promote the growth of treated animals or to increase yields from treated animals.

\section{PART B}

A Medicinal products developed by other biotechnological processes which, in the opinion of the Agency, constitute a significant innovation.

$\Delta$ Medicinal products administered by means of new delivery systems which, in the opinion of the Agency, constitute a significant innovation.

$\Delta$ Medicinal products presented for an entirely new indication which, in the opinion of the Agency, is of significant therapeutic interest.

A Medicinal products based on radio-isotopes which, in the opinion of the Agency, are of significant therapeutic interest.

$\boldsymbol{\Delta}$ New medicinal products derived from human blood or human plasma.

$\boldsymbol{\Delta}$ Medicinal products the manufacture of which employs processes that, in the opinion of the Agency, demonstrate a significant technical advance such as two-dimensional electrophoresis under micro-gravity.

$\Delta$ Medicinal products intended for administration to human beings, containing a new active substance which, on the date of entry into force of this regulation, was not authorized by any Member State for use in a medicinal product intended for human use.

A Veterinary medicinal products intended for use in foodproducing animals containing a new active substance which, on the date of entry into force of this Regulation, was not authorized by any Member State for use in food-producing animals.

Source: Council Regulation of 22 July 1993 laying down Community procedures for the authorization and supervision of medicinal products for human and veterinary use and establishing a European Agency for the Evaluation of Medicinal Products. EEC No2309/93. The Rules Governing Medicinal Products in the European Union. Vol. I. 